\title{
Influence of Tourist Pressure on Beach Litter and Microbial Quality - Case Study of Two Beach Resorts in Ghana
}

\author{
Sitsofe A. Tsagbey, Adelina M. Mensah and F. K. E. Nunoo \\ Department of Oceanography and Fisheries, University of Ghana, P. O. Box LG 99, Legon, Accra, Ghana \\ Corresponding author; E-mail: ammensah@ug.edu.gh
}

\begin{abstract}
Beach litter accumulation and reduced water quality are important aspects of beach degradation which have adverse effects on the users of the beach and marine life. The study aims at determining how the degree of human pressure at the La and Korle Beach resorts in Accra, Ghana, which serve different social communities, contributes to beach degradation. A weekly collection of fresh and accumulated litter from a belt transect of $500 \mathrm{~m}^{2}$ and samples of seawater from each beach were obtained during a 3-week festive period (Dec. 26, 2005-Jan. 9, 2006) and a 3-week non-festive period (Jan. 23, 2006-Feb. 6, 2006). Thirty-two types of litter were identified and the total number and weight of litter collected from La were 2261 and 72695 g, and that of Korle were 2691 and 43239 g, respectively. Plastic material dominated the total litter at $66 \%$ for Korle and $53 \%$ for La, respectively. The numbers of litter increased with increasing visitor pressure during the festive season for Korle, although the type and diversity of the beach litter was location specific irrespective of the season for both sites. Microbial values for coliforms were higher for Korle than La, with significant increase in Korle during the festive season. The implications for leisure activity like swimming at both sites has minimal health risks since the mean levels of the indicators are within the WHO international permissible range.
\end{abstract}

\section{Introduction}

There has been remarkable population growth in recent years accompanied by rapid urbanization and a relative increase in industrial activities, particularly in many developing countries in Africa and Asia. These transformations have resulted in a significant increase in the amount of solid waste and a wider diversification of various types of pollutants (including beach litter) that reach the coast and sea. This has led to the degradation of coastal and marine areas with many environmental, social and economic implications, especially the promotion of coastal tourism. Attempts to address the pervasive menace of poor sanitation of coastal areas by various African and Asian governments, private sector, civil society, universities and research institutions, community-based organisations and non-governmental organisations have been woefully inadequate mainly because of the enormous volume of solid waste generated, inadequate waste management infrastruc-ture and non-efficient waste management system in place.

Worldwide, as many as 8 million items of litter may enter the seas on daily basis (Benton, 1995). It has been estimated that the weight of rubbish three times the weight of caught fish is dumped into the world's oceans annually (Nunoo \& Quayson, 2003). This litter, which come from numerous sources may, generally, be grouped into land- and aquatic-based sources. Land based sources include industrial effluents, washed-off debris from run-off and inappropriately managed garbage bins, litter from holiday-makers at beaches, and garbage dumping grounds in communities. Aquatic-based litter include solid waste carried by rivers, and litter from merchant ships and fishing vessels (Williams et al., 1993; Debrot et al., 1999; Williams et al., 2000). These items may persist and/or drift in the ocean or eventually become deposited along coastal areas. For instance, some of the litter, often the smaller pieces, become buried and re-emerge at later times to compound the litter problem at beaches (Williams \& Tudor, 200; Nagelkerken et. al., 2001; Kusui \& Noda, 2003).

There is a general perception that litter at beaches, especially those from recreational sources, accumulate in larger quantities in the festive and rainy seasons compared to the non-festive and dry seasons in a year. In addition, the viability of the ecosystem is threatened by the smothering of less mobile or immobile organisms such as corals, reduced primary productivity; and decreased fecundity as a result of reduction in effective feeding and destruction of spawning grounds (Connors \& Smith, 1982; Bourne \& Clark, 1984; Laist, 1987).

Beach litter also pose a threat to the health status of beach users and inhabitants of adjacent communities. Litter from medical sources, such as syringes, glass pieces and metallic objects, threaten the health of tourist and render the beach unsafe to the users. The economic implications are equally important, given that the tourism industry in Ghana, which is currently considered to be the fourth largest source of foreign exchange earnings, can be adversely affected (Ghana Tourist Board, 2005).

It was estimated that tourist earnings totaled US\$ 650 million in 2004, and contributed approximately 5\% to the country's GDP. Tourist arrivals in Ghana have steadily increased over the past 15 years from approximately 145,000 in 1990 to 600,000 in 2004. As beach litter devalue the aesthetic value of the beach, where most tourists visit to relax, it can serve as a deterrent to future visitors. Other economic activities, such as marine transportation, can be adversely affected, including trawling operations, which make it dangerous to navigate, leading to loss of fishing time and financial income (Nash, 1992).

West African Journal of Applied Ecology, vol. 15, 2009 
In Ghana, the most common types of litter include pieces of fishing net, foam, foot wear, cloth, charcoal, wood, and husk of sugar cane and coconut (Nunoo \& Quayson, 2003). Faecal deposits also frequently occur, especially in areas where the adjacent communities do not have adequate toilet facilities. With tidal cycles, these deposits are washed into the sea and degrade the quality of the water. There is also direct sewage disposal into the sea (Nunoo \& Evans, 2007), which can cause health hazard to both the users of the beach and sea biota. These obscene environmental impacts are happening amidst the existence of many local policies while Ghana is a signatory to many international conventions, including the convention against marine pollution (MARPOL), United Nations Law of the Sea (UNLOS), and Convention of Biological Diversity (CBD).

The study aims at comparing beach degradation at two resorts in Accra, which have different socioeconomic conditions during festive and non-festive periods, to reflect high and low visitor pressure, respectively. The specific objectives of the study were first, to determine the quantity and type of beach litter generated, and, secondly, to assess the level of coliform (total and faecal) and Vibrio cholerae in coastal shore waters, for each site and period.

Specific information on the types of beach litter generated and microbial quality during festive seasons as compared to non-festive period in the different socio-economic settings will enable environmental managers to incorporate the social influences in managing beach degradation. It is expected that the information obtained from the study will raise awareness and contribute to effective management, thereby, improving the environmental quality of beaches in Ghana.

\section{Materials and methods}

Study area

The sites chosen for the study were the La Pleasure Beach and the Korle Gonno Beach Resort (Fig. 1), with differing socio-economic settings and various categories of tourists. La Pleasure Beach is located off the Accra-Teshie/Nungua Road (Lat. 05 $33^{\circ} 44.9^{\prime \prime} \mathrm{N}$ and $05^{\circ} 33^{\prime} 43.8^{\prime \prime} \mathrm{N}$ and Long. 00 08' 21.2" W and $00^{\circ} 08^{\prime}$ 19.5" W). This beach shares boundaries with 4-Star La Palm Royal and 5-Star La Pleasure Beach hotels, and is patronised throughout the week by both foreign and local tourists. Korle Beach Resort (Lat. 05 $31^{\prime}$ 42.0" $\mathrm{N}$ and $05^{\circ} 31^{\prime} 42.9^{\prime \prime} \mathrm{N}$ and Long. $00^{\circ} 13^{\prime} 41.0^{\prime \prime} \mathrm{W}$ and $00^{\circ} 13^{\prime} 39.1^{\prime \prime} \mathrm{W}$ ) is located on the western side of Accra in the densely populated community of Korle Gonno, which is well-noted nationwide for its degraded environmental conditions (Nunoo \& Evans, 2007). Beach visitors are normally local tourists who go there mostly on holidays and weekends. 


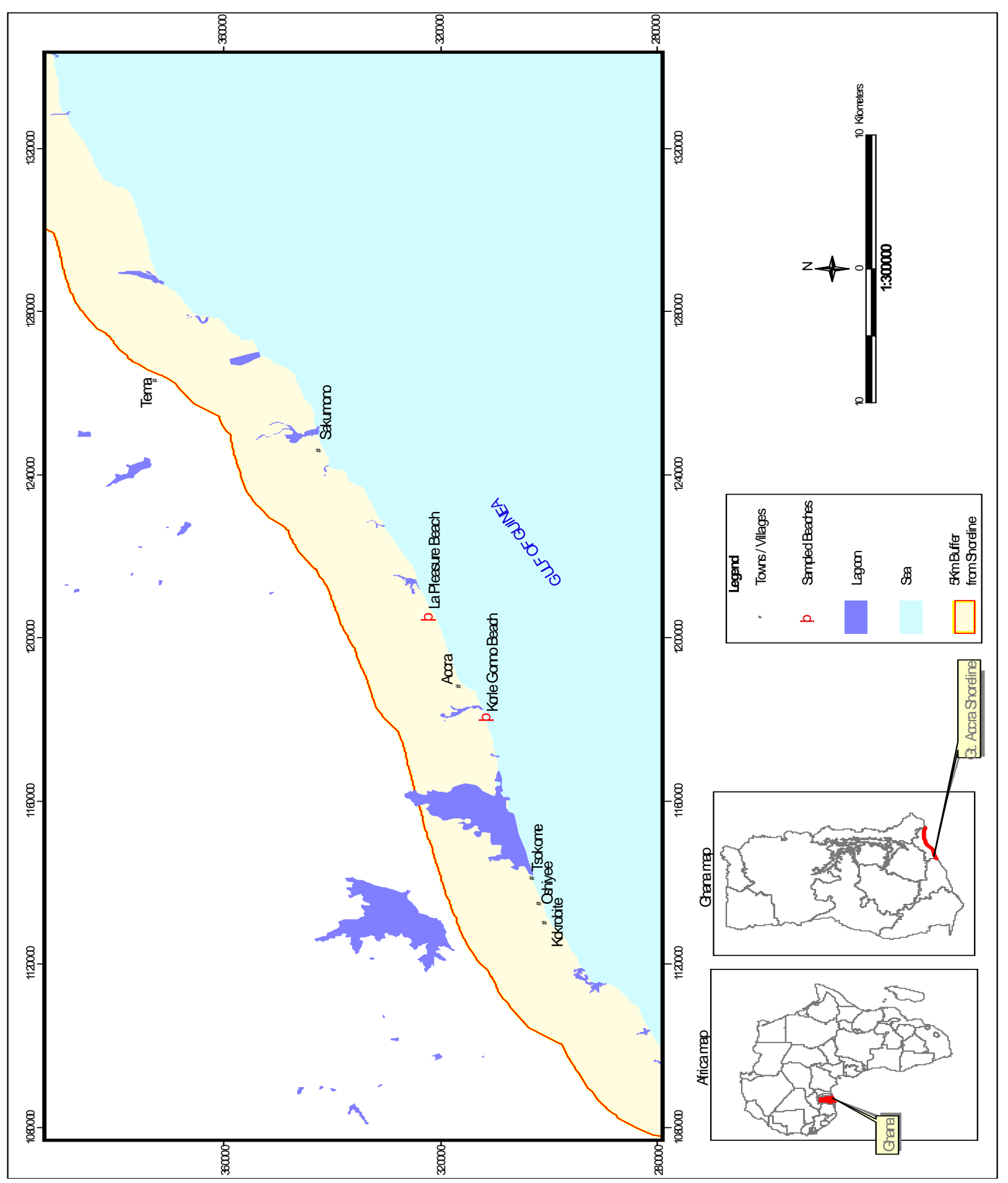

Fig. 1. Map showing locations of La Pleasure and Korle beaches in Accra, Ghana

Field and desk methods

A belt transect, representing a sampling area of $500 \mathrm{~m}^{2}$ (i.e. $5 \mathrm{~m} \times 100 \mathrm{~m}$ ) was demarcated on the upper and mid shore of each beach. This method has the advantage of assessing both fresh and accumulated beach litter and provides a better chance of surveying both clean and dirty areas (Velander \& Mocogni, 1999). Beach litter and water samples were collected once every week for 3 weeks during the festive Christmas and New Year period (26 Dec. 2005-9 Jan. 2006) and once every week for 3 weeks during a period with less celebrations (23 Jan. 2006-6 Feb. 2006). On each visit, all the litter within the belt was raked and collected into sacks and transported to the laboratory for sorting and weighing.

Employing Millipore (1986) methodology, sea water was collected into a 1-litre sterile bottle and analysed at the Microbiology Laboratory at the Water Research Institute of the Council for Scientific and Industrial Research (CSIR) for total coliform (TC), faecal coliforms (FC) and Vibrio cholerae, determined by the 
Membrane filter (MF) method. Simple T-test and Bray Curtis similarity index were used in the data analyses with Statistical Package for Service Solutions (SPSS) and PRIMER.

\section{Results}

Table 1 shows a list of 32 identified items of beach litter deposited on the beaches during the study with six of them being members of the famous "dirty dozen". Using the United Nations Environmental Programme (UNEP, 1990) classification, there were no fishing gears and equipments on both sites. Nearly all of the litter (99\%) can be placed in the third group, which is the non-degradable plastic, and miscellaneous litter from both land and oceans sources. In fact, plastics dominated the catch, forming about $66 \%$ at Korle and 53\% at La of the total number of items recorded.

TABLE 1

Relative composition of litter sampled from La Pleasure Beach and Korle Beach Resort (italics show those in the world's 'dirty dozen')

\begin{tabular}{|c|c|c|c|c|c|}
\hline \multirow[t]{2}{*}{$N$} & \multirow[t]{2}{*}{ Types of litter } & \multicolumn{2}{|c|}{ La Pleasure Beach } & \multicolumn{2}{|c|}{ Korle Beach Resort } \\
\hline & & Total No. & Total Wt $(g)$ & Total No. & Total Wt $(g)$ \\
\hline 1 & Aluminium foils & 2 & 15 & 9 & 95 \\
\hline 2 & Back pack & 1 & 32500 & 0 & 0 \\
\hline 3 & Biscuit wrappers & 149 & 965 & 286 & 1188 \\
\hline 4 & Black polythene & 84 & 2440 & 194 & 3477 \\
\hline 5 & Bones & 120 & 231 & 49 & 1270 \\
\hline 6 & Charcoal & 5 & 75 & 0 & 0 \\
\hline 7 & Clothes & 15 & 510 & 22 & 443 \\
\hline 8 & Coconut husk & 3 & 475 & 0 & 0 \\
\hline 9 & Comb & 1 & 10 & 0 & 0 \\
\hline 10 & Corn comb & 0 & 0 & 2 & 50 \\
\hline 11 & Crown cork & 109 & 220 & 174 & 473 \\
\hline 12 & Disposable plates and spoons & 95 & 379 & 48 & 837 \\
\hline 13 & Footwear pieces & 5 & 210 & 2 & 304 \\
\hline 14 & Fruit peels & 5 & 110 & 19 & 5667 \\
\hline 15 & Glass pieces & 30 & 6525 & 9 & 6044 \\
\hline 16 & Kenkey peels & 1 & 5500 & 5 & 1675 \\
\hline 17 & Khebab sticks & 170 & 745 & 233 & 808 \\
\hline 18 & Metal beverage cans & 58 & 2720 & 64 & 2635 \\
\hline 19 & Metal pieces & 3 & 450 & 0 & 0 \\
\hline 20 & Paper drink pack & 55 & 1185 & 50 & 2352 \\
\hline 21 & Paper pieces & 395 & 2145 & 272 & 2728 \\
\hline 22 & Pieces of cigarettes & 55 & 10 & 23 & 10 \\
\hline 23 & Plastic containers & 113 & 1550 & 118 & 1896 \\
\hline 24 & Pure water sachet & 408 & 5125 & 803 & 5230 \\
\hline 25 & Straws (plastic) & 59 & 25 & 39 & 108 \\
\hline 26 & Syringe & 1 & 10 & 0 & 0 \\
\hline 27 & Used battery & 0 & 0 & 3 & 3 \\
\hline 28 & Used sanitary pads & 0 & 0 & 3 & 3 \\
\hline 29 & Used pampers & 1 & 150 & 3 & 352 \\
\hline 30 & Waste food & 2 & 195 & 1 & 1848 \\
\hline 31 & White polythene & 306 & 8150 & 283 & 3728 \\
\hline 32 & Yarns & 10 & 90 & 0 & 0 \\
\hline \multicolumn{2}{|c|}{ Total } & 2261 & 72695 & 2691 & 43239 \\
\hline \multicolumn{2}{|c|}{ Mean } & s70.66 & 2271.72 & 86.81 & 1394.81 \\
\hline \multicolumn{2}{|c|}{ Std error of mean } & 19.49 & 1043.86 & 29.28 & 322.03 \\
\hline
\end{tabular}

The total number of beach litter for both festive and non-festive periods recorded for Korle was 2691 and 2261 for La. The total litter weight for Korle was 43,239 g and that for La was 72,695 g. The number of beach litter recorded for the festive season was higher than that for the non-festive (Table 2). Bray-Curtis similarity cluster analysis showed that at $75 \%$ similarity, the number of beach litter at each of the study areas 
during the festive period is similar to that of the non-festive time. However, at Bray-Curtis similarity of 85\%, the diversity of litter showed significant differences between seasons and sites.

TABLE 2

Relative composition by numbers of litter sampled from La Pleasure Beach and Korle Beach Resort during the festive and non-festive seasons

\begin{tabular}{|c|c|c|c|c|c|}
\hline \multirow[t]{2}{*}{ No. } & \multirow{2}{*}{ Types of litter } & \multicolumn{2}{|c|}{ Festive season } & \multicolumn{2}{|c|}{ Non-festive season } \\
\hline & & $\begin{array}{l}\text { La Pleasure } \\
\text { Beach }\end{array}$ & $\begin{array}{l}\text { Korle Beach } \\
\text { Resort }\end{array}$ & $\begin{array}{c}\text { La Pleasure } \\
\text { Beach }\end{array}$ & $\begin{array}{l}\text { Korle Beach } \\
\text { Resort }\end{array}$ \\
\hline 1 & Aluminum foils & 1 & 5 & 1 & 4 \\
\hline 2 & Bag & 1 & 0 & 0 & 0 \\
\hline 3 & Biscuit rappers & 73 & 189 & 76 & 97 \\
\hline 4 & Black polythene & 39 & 137 & 45 & 57 \\
\hline 5 & Bones & 100 & 44 & 20 & 5 \\
\hline 6 & Charcoal & 3 & 0 & 2 & 0 \\
\hline 7 & Clothes & 10 & 14 & 5 & 8 \\
\hline 8 & Coconut husk & 3 & 0 & 0 & 0 \\
\hline 9 & Comb & 1 & 0 & 0 & 0 \\
\hline 10 & Corn comb & 0 & 2 & 0 & 0 \\
\hline 11 & Crown cork & 41 & 144 & 68 & 30 \\
\hline 12 & Disposable plates and spoons & 1 & 36 & 94 & 12 \\
\hline 13 & Footwear pieces & 2 & 1 & 3 & 1 \\
\hline 14 & Fruit peels & 3 & 14 & 2 & 5 \\
\hline 15 & Glass pieces & 13 & 7 & 17 & 2 \\
\hline 16 & Kenkey peels & 1 & 5 & 0 & 0 \\
\hline 17 & Khebab sticks & 76 & 44 & 94 & 189 \\
\hline 18 & Metal cans & 26 & 36 & 32 & 28 \\
\hline 19 & Metal pieces & 3 & 0 & 0 & 0 \\
\hline 20 & Paper drink pack & 8 & 50 & 47 & 0 \\
\hline 21 & Paper pieces & 226 & 173 & 169 & 99 \\
\hline 22 & Pieces of cigarettes & 32 & 0 & 23 & 0 \\
\hline 23 & Plastic containers & 55 & 95 & 58 & 23 \\
\hline 24 & Pure water sachet & 261 & 555 & 147 & 248 \\
\hline 25 & Straws & 7 & 21 & 52 & 18 \\
\hline 26 & Syringe & 1 & 0 & 0 & 0 \\
\hline 27 & Used battery & 0 & 0 & 0 & 3 \\
\hline 28 & Used sanitary pads & 0 & 0 & 0 & 3 \\
\hline 29 & Used pampers & 0 & 2 & 1 & 1 \\
\hline 30 & Waste food & 0 & 0 & 2 & 1 \\
\hline 31 & White polythene & 221 & 190 & 85 & 93 \\
\hline 32 & Yarns & 10 & 0 & 0 & 0 \\
\hline \multicolumn{2}{|c|}{ Total } & 1218 & 1764 & 1043 & 927 \\
\hline \multicolumn{2}{|c|}{ Mean } & 45.11 & 84 & 47.41 & 44.14 \\
\hline \multicolumn{2}{|c|}{ Std. error of mean } & 14.26 & 27.6 & 10.26 & 14.66 \\
\hline
\end{tabular}

A simple T-test at 95\% confidence level (0.05 significant level) indicates that there is no significant variation between the total beach litter for Korle and La, between Korle festive and La festive periods, between Korle non-festive and La non-festive occasions, or between festive and non-festive periods for La. However, at Korle there was significant variation $(P=0.011)$ between the festive and non-festive periods (Table 2).

TABLE 3

Significance (P-values) levels for simple T-test for beach litter

\begin{tabular}{lcccc} 
& Korle festive & La festive & Korle non-festive & La non-festive \\
\hline Korle Festive & - & 0.094 & 0.011 & - \\
La Festive & 0.094 & - & - & - \\
Korle Non-festive & 0.011 & 0.450 & 0.104 & 0.104 \\
La Non-festive & - & & & - \\
\hline
\end{tabular}


During the festive season, Korle recorded relatively higher values than La in all the analyses, with Vibrio cholerae levels being the highest. At La, Vibrio cholerae also recorded the highest level. At both sites, FC levels were minimal. The same trend was noticed during the non-festive with Vibrio cholerae at Korle, recording the highest, and FC at $\mathrm{La}$, the lowest. Simple T-test at significant level of 0.05 indicates that there is a significant variation between both seasons for FC and Vibrio cholerae at Korle, and no significant variation in TC for both seasons for both sites, or FC and Vibrio cholerae at La only.

\section{Discussion}

Beach litter deposited at the two tourist beaches in Accra consisted of 32 individual items of which six are on the list of the world's “dirty dozen". This litter originates from various sources such as beach visitor's (tourists) litter, household litter and other land-based sources. Metallic objects formed $8 \%$ of the total litter at La and 9\% at Korle. Plastic materials (non-degradable) were found to be the most common litter, like in several places in the world (UNEP, 1990; Topping et al., 1994; Hoagland \& Kitte, 1997; Nunoo \& Quayson, 2003).

In the study, plastics formed about $66 \%$ at Korle and $53 \%$ at La of the total number of litter found, which is not significantly different from that of the beach litter survey of Sakumono Beach and Centre for National Culture Beach by Nunoo \& Quayson (2003), which recorded between $46 \%$ and $58 \%$. The larger percentage of litter at Korle than La could be attributed to the low educational level of people on environmental awareness and behaviour (Santos et al., 2005) at Korle compared to that of the people of La. The quantities of plastics recorded at Ghanaian beaches compare favourably with that found along the Sea of Japan which was 40-80\% of total weight and number, respectively (Kusui \& Noda, 2003).

From personal communication with managers at the La Pleasure Bbeach, it was established that beach litter increases during the rainy season when runoff transports land litter to the beach. At La, for instance, there is a drainage system from the township, which ends up in the sea at about $200 \mathrm{~m}$ from the Pleasure Beach. During the rainy season, accumulated litter in the drain are emptied into the sea with runoff. At Korle, the Korle Gonno community is found close to the shore and the inhabitants use the beach shore as a refuse dump and place of convenience. At the Korle Beach Resort, no faecal deposits were observed, which is most probably due to the fact that this portion of the beach is managed. However, a few metres away from the beach resort, the popularly known "Lavender hill" (where septic sewage from homes in Accra is directly discharged into the sea) is located about $500 \mathrm{~m}$ away.

The Bray-Curtis similarity cluster analysis shows that at $75 \%$ similarity, the number of beach litter at both Korle and La, during the festive period, is similar to that of the non-festive period at Korle. This implies that at $75 \%$ similarity, diversity of the beach litter is location specific irrespective of the period. The type of beach litter is, therefore, not determined by the seasons, the number of tourists, or increased pressure to the beach, but by where it is located.

Simple T-test shows that there is significant variation $(P=0.011)$ between the festive and non-festive periods for Korle but not for La. Although Korle Beach Resort is a tourist beach, it is patronized mostly by the local Korle Gonno community and, on a lager scale, during festive occasions such as Christmas, Easter and public holidays (pers. comm. from Resort managers). At La Pleasure Beach, the constant stream of guests from the adjacent hotels, the numerous entertainment establishments (i.e. bars and restaurants) located directly on the beach front, in addition to its central location in the city, guarantee a fairly stable patronage. Hence, the variation between the beach litter for the festive and non-festive seasons was observably insignificant.

Korle Beach Resort recorded relatively higher microbial levels for all the three indicators. Water quality at Korle is more degraded than La, and can be attributed to very poor environmental conditions around the beach resort, including direct sewage discharge at the "lavender hill" and the use of the beach as a place of convenience by the community. Simple T-test at significant level of 0.05 indicates significant variation $(P=$ 0.044) in FC levels between the festive season and non-festive season at Korle, which may be the result of increased numbers of visitors who may also use the beach as place of convenience. Another probable cause could be a discharge from the sewage outlets around the sampling period, which will need to be investigated as an important consideration for health workers and the community.

Comparing the mean levels of TC and FC at both sites to the WHO international standards (APHAAWWA-WPCF, 2001), sea water at both beaches is at undesirable levels for intake, i.e. a swimmer who gulps some amount of water when swimming may develop some health issues such as gastroin-testinal illness, eye, ear and skin infections. For primary contact, i.e. swimming, the levels of the coliform (total and faecal) at both beaches compared to WHO international standards were found to be permissible, but not desirable. For fishing and boating, the levels of coliform are within the acceptable range.

West African Journal of Applied Ecology, vol. 15, 2009 
The study has shown a need for action to curtail rapid degradation of coastal environments in order not to derail the gains so far made in the tourism industry in Ghana. The authors join Fobil \& Hogarth (2006) in calling for the institution and enforcement of the polluter pays principle through levying within a comprehensive and sustainable waste management system. Plastic litter can also be re-used through recycling processes and this should be encouraged. Further, source separation of solid wastes in homes, factories and public places or, better still, at landfill sites should be given some attention by municipal authorities to help rid the beaches and cities of filth. A mass education drive to elicit changes in perception, attitudes and behaviour in order for the populace to embrace the practice of environmental cleanliness should be undertaken, and this should be supported by sanitation infrastructure provision in all coastal areas.

\section{Conclusion and recommendations}

Thirty-two (32) individual items were identified at both Korle Beach Resort and La Pleasure Beach, of which six are on the list of the world's "dirty dozen". Non-degradable plastics formed the majority of the beach litter on each site and the type and diversity of the beach litter were location specific, irrespective of the festive and non-festive seasons. There was, however, significant variation in numbers of litter between the festive and non-festive only at Korle, which indicates a significant increase in patronage during the festive season. At La, the variation was not significant between seasons as the beach is a popular social centre surrounded by many hotels, and, therefore, more frequented by tourists.

The mean levels of FC and TC in the water at Korle Beach Resort were relatively higher than that of the La Pleasure Beach. Swimming in the waters at both sites has minimal health risks since the mean levels of the faecal and total coliform are above the WHO international desirable range but well within the permissible range.

With the information obtained on type, number and weight of litter generated, appropriately designed litterbins can be placed at vantage points in order to reduce the quantity of litter that ends up on the shore, especially plastics. Since litter are washed out of the open drainage systems, appropriate management processes to clean the drains must be implemented. Communities should be intensely educated on health and environmental hazards and also encouraged with the provision of appropriate facilities. This can be started with identifiable coastal community groupings in, for instance, the Central and Western regions called the 'Asafo companies'. Other com-munity focal groups, such as school children (Nunoo \& Evans, 2007), identifiable trade and product organisations, and opinion leaders can be sensitised to elicit attitudinal and behavioural change towards proper and safe littering habits.

Regular microbial analysis of water must be carried out on various beaches to ensure that the quality of the water is within the permissible range, especially in beaches near sewage outlets. This will provide information needed to minimise health risks to communities and enable better management of sewage disposal. In situations where the quality is poor, the beach should be closed down to the public. Signposts should be placed at vantage points warning the public not to dump refuse at prohibited places and offended persons prosecuted. In places where these are already present, efforts should be made to enforce the laws.

\section{Acknowledgement}

The authors express their appreciation to Dr H. R. Dankwa, Dr J. A. Ampofo (both of Water Research Institute, CSIR, Accra), Dr George Wiafe (Department of Oceano-graphy and Fisheries, University of Ghana) and George Fitzberg Nunoo (Accra) for their immense help in the sampling process and laboratory work.

\section{References}

Benton T. G. (1995). Marine litter in Pitcairn Island. Pitcairn Island Special Issue 56: 415-422.

Bourne W. R. P. and Clark J. (1984). The occurrence of bird and garbage at Humboldt from off Valparaso, Chile. Mar. Pollut. Bull. 15: $343-344$.

Connors P. G. and Smith K. G. (1982). Oceanic plastic particles pollution: Suspended effects on deposition in red Phalaropes. Mar. Pollut. Bull. 13: 18-20.

Debrot A. O., Tiel A. B. and Bradshaw J. E. (1999). Beach debris in Curacao. Mar. Pollut. Bull. 38: 795-801.

APHA-AWWA-WPCE (2001). Standards methods for the examination of water and wastewater, 19th edn. American Public Health Association (APHA), American Water Works Assocciation (AWWA) and Water Environment Federation WEF), USA.

Fobil J. N. and Hogarth J. N. (2006). The dilemmas of plastic wastes in a developing economy: proposals for a sustainable management approach for Ghana. West Afr. J. appl. Ecol. 10: 221-229.

Ghana Tourist Board (2005). Ghana Tourist Statistical Sheet. Accra, Ghana.

Hoagland P. and Kitte-Powell H. L. (1997). Characterisation and mitigation of marine debris in the Gulf of Maine. A report prepared for the US Gulf of Maine Association. Contract No. GM 97-13. Woods Hole Research Consortium. 36 pp.

Kasui T. and Noda M. (2003). International survey on the distribution of stranded and buried litter on beaches along Sea of Japan. Mar. Pollut. Bull. 47: 175-179.

West African Journal of Applied Ecology, vol. 15, 2009 
Laist D. W. (1987). Overview of the biological effects of lost and discarded plastic debris in the marine environment. Mar. Pollut. Bull. 18: 319-326.

Millipore (1986). Water Microbiology Laboratory and Field Procedures. Millipore Corporation. USA.

Nagelkerken I., Wiltjer G. A. M., Debrot A. O. and Pors L. P. J. J. (2001). Baseline study of submerged marine debris at beaches in Curacao, West Indies. Mar. Pollut. Bull. 42: 789-789.

Nash A. D. (1992). Impact of marine debris on subsistence fishermen. Mar. Pollut. Bull. 24: 150-155.

Nunoo F. K. E. and Evans S. M. (2007). Citizenship in a Ghanaian school: students' contribution to sustainable management of the coastal environments. Sch. Sci. Rev. 88: 107-114.

Nunoo F. K. E. and Quayson E. (2003). Towards management of litter accumulation - case study of two beaches in Accra, Ghana. J. Ghana Sci. Assoc. 5: 145-155.

Santos I. R., Friedrich A. C. Wallner-Kersanach M. and Fillman G. (2005). Influence of socio-economic characteristics of beach users on litter generation. Ocean Coast Mgmt 28: 742-752.

Topping P., Eade A. and Eaton P. (1994). Marine plastic debris research in Canada. Paper presented at the 3rd International Conference on Marine Debris, Miami, Florida, May 1994. Marine Environment Division, Canada.

UNEP (1990). The problem of persistent plastics and marine debris in the oceans. GESAMP: The state of the marine environment. UNEP Regional Seas Reports and Studies No. 115.

Velander K. and Mocogni M. (1999). Beach litter sampling strategies: is there a 'best method'? Mar. Pollut. Bull. 38: 1134-1140.

Williams A. T., Williams A. T., Simmons S. L. and Fricker A. (1993). Off-shore-sinks of marine litter: a new problem. Mar. Pollut. Bull. 26: 404-405.

Williams A. T., Morgan R. and Tudor D. (2000). Beach litter from land-based activities. InterCoast Spring 25-26.

Williams A. T. and Tudor D. T. (2001). Litter burial and exhumation: spatial and temporal distribution on a cobble pocket beach. Mar. Pollut. Bull. 42: 1031-1039. 